Bidang Ilmu: Kesehatan

\title{
ANALISIS PERBEDAAN PENGETAHUAN REMEJA PUTRI SEBELUM DAN SESUDAH DIBERIKAN PENYULUHAN MENGENAI MENARCH DAN MENSTRUASI DI SMK BHAKTI MULIA KEDIRI
}

\author{
Yuli Admasari ${ }^{1)}$, Astri Yunita1), Febrina Dwi Nurcahyanti1) \\ Program Studi DIII Kebidanan, STIKes Bhakti Mulia, Kediri1) \\ email: admasariyuli@gmail.com
}

\begin{abstract}
ABSTRAK
Pengetahuan atau knowledge adalah hasil dari manusia terdiri dari sejumlah fakta dan teori yang memungkinkan seseorang untuk dapat memecahkan masalah yang dihadapinya. Menstruasi atau haid adalah peristiwa alamiah yang dialami setiap perempuan. Penelitian ini bertujuan untuk mengetahui perbedaan pengetahuan remaja putri kelas $X$ sebelum dan sesudah diberi penyuluhan mengenai menarche dan menstruasi di SMK Bhakti Mulia Tahun 2020. Jenis penelitian ini analitik dan dengan pendekatan cross sectional. Sasaran dalam penelitian ini adalah 60 remaja putri. Hasil penelitian menunjukan pengetahuan remaja putri sebelum diberi penyuluhan mengenai menarche dan menstruasi dengan nilai rata-rata 73.0667. Pengetahuan remaja putri kelas VII sesudah diberi penyuluhan mengenai menarche dan menstruasi dengan nilai rata-rata 80.2000. Hasil uji t-tes paired menghasilkan rata- rata perbedaan nilai pengetahuan sebelum dan sesudah diberikan penyuluhan mengenai menarche dan menstruasi adalah -7.13333 dan nilai $p=0,000$. Perlu adanya kerjasama guru dan orang tua dalam memberikan pendidikan kesehataan terutama mengenai menarche dan menstruasi. Diharapkan remaja putri dapat meningkatkan pengetahuan mengenai menarche dan menstruasi dengan mengikuti penyuluhan mengenai kesehatan reproduksi.
\end{abstract}

Kata kunci: pengetahuan, remaja putri, menarche, menstruasi

\begin{abstract}
Knowledge is a result of a human being consisting of a number of facts and theories that enable one to be able to solve the problem he faced. Menstruation or menstruation is a natural event experienced by each woman. This research aims to determine the difference in the young women's class X before and after given counseling about the target and menstruation at SMK Bhakti Mulia, 2020. This type of research is analytic and with cross sectional approach. The goal in this study was 60 young women. The results showed the young women's knowledge before being given counseling on the menarche and menstruation with an average value of 73.0667. Young women's knowledge of class VII after being given counseling about menarche and menstruation with an average value of 80.2000. The results of the T-Test paired resulted in an average difference in the value of the knowledge before and after given the counseling about the menarche and the menstrual period is-7.13333 and the value $P=0,000$. There is a need for the cooperation of teachers and parents in providing a health education especially about the menarche and menstruation. It is hoped that young women can improve their knowledge of menarche and menstruation by following counseling about reproductive health.
\end{abstract}

Keywords: knowledge, young women, menarche, menstruation 


\section{PENDAHULUAN}

Pengetahuan merupakan hasil "tahu" dan ini terjadi setelah orang melakukan pengindraan terhadap suatu objek tertentu. Pengindraan terjadi melalui panca indera manusia yakni panca indra penglihatan, pendengaran, penciuman, rasa dan raba. Sebagian besar pengetahuan manusia diperoleh melalui mata dan telinga. Pengetahuan atau kognitif merupakan dominan yang sangat penting dalam membentuk tindakan seseorang (over behavior) (Notoatmodjo, 2015). Setiap kehidupan manusia diawali dengan beberapa tahap perkembangan. Perkembangan manusia berawal dari masa prenatal sampai menjelang akhir kehidupan yang dikenal dengan usia lanjut. Dalam setiap periode perkembangan terdapat berbagai tugas perkembangan yang harus dilalui dan setiap aspek perkembangan baik fisik, emosi, intelegensi maupun sosial (V., E., \& A, 2010).

Perkembangan remaja memang suatu fenomena yang penting untuk kita bahas, berikut beberapa klasifikasi perkembangan remaja yang pertama. Perkembangan Fisik yaitu dimana perubahan dramatis dalam bentuk dan ciri-ciri fisik berhubungan erat dengan mulainya pubertas (Ameade \& Garti, 2016). Aktivitas kelenjar pituitari pada saat ini berakibat dalam sekresi hormon yang meningkat, dengan efek fisiologis yang tersebar luas. Hormon pertumbuhan memproduksi dorongan pertumbuhan yang cepat, yang membawa tubuh mendekati tinggi dan berat dewasanya dalam sekitar dua tahun (Khan, Jha, \& Ansari, 2020).

Remaja berasal dari kata latin adolescere (kata bendanya adolescentra yang berarti remaja) yang berarti "tumbuh" atau tumbuh menjadi dewasa. Istilah adolescence, seperti yang dipergunakan saat ini mempunyai arti yang lebih luas mencakup kematangan mental, emosional, sosial dan fisik (Erbil, Felek, \& Karakaşl1, 2015). Awal masa remaja berlangsung kira-kira 13 tahun sampai 16 atau 17 tahun, dan akhir masa remaja bermula dari usia 16 atau 17 tahun sampai 18 tahun, yaitu usia matang secara hukum. Dengan demikian akhir masa remaja merupakan periode yang sangat singkat (Hurlock, (Kobayashi, Koyama, Yasutomi, \& Sankai, 2018).

Masa remaja merupakan salah satu tahap dalam kehidupan manusia yang sering disebut sebagai masa pubertas yaitu masa peralihan dari anak-anak ke masa dewasa. Pada tahap ini remaja akan mengalami suatu perubahan fisik, emosional dan sosial sebagai ciri dalam masa pubertas. Dan dari berbagai ciri pubertas tersebut, menarche merupakan perbedaan yang mendasar antara pubertas pria dan pubertas wanita (Nehulkar, Holambe, \& Thakur, 2016). Menarche adalah saat haid/menstruasi yang datang pertama kali yang sebenarnya merupakan puncak dari serangkaian perubahan yang terjadi pada seorang remaja putri yang sedang menginjak dewasa dan sebagai tanda bahwa ia sudah mampu hamil. Usia remaja putri saat mengalami menarche bervariasi lebar, yaitu antara usia 10-16 tahun, tetapi rata-rata pada usia 12,5 tahun. Statistik menunjukkan bahwa usia menarche dipengaruhi faktor keturunan, keadaan gizi dan kesehatan umum (Diaris \& Pramita, 2019).

Menurut WHO (2018) sekitar seperlima dari penduduk dunia adalah remaja berusia 10-19 tahun. Sekitar 900 juta berada di negara sedang berkembang. Data demografi di Amerika Serikat (2018) menunjukkan jumlah remaja berumur 10-19 tahun. Sekitar $15 \%$ populasi. Di Asia Pasifik dimana penduduknya merupakan $60 \%$ 
dari penduduk dunia, seperlimanya adalah remaja umur 10-19 tahun. Di Indonesia menurut Biro Pusat Statistik (2018) kelompok umur 10-19 tahun adalah sekitar 22\% yang terdiri dari 50,9\% remaja laki-laki dan 49,1\% remaja perempuan (Riskesdas, 2018).

Sedangkan jumlah penduduk di propinsi Jawa Timur tahun 2019 adalah 6.983.699 jiwa dan jumlah remaja usia 10-14 tahun adalah 714.615 jiwa sedangkan yang berusia 15-19 tahun adalah 761.516 jiwa (BPS Jawa Timur, 2019). Di SMK Bhakti Mulia terdapat 820 siswa yang terdiri dari 399 siswa laki - laki dan 421 siswa perempuan. Sedangkan jumlah siswa untuk kelas $X$ berjumlah 285 yang terdiri dari 136 siswa lakilaki dan 149 siswa perempuan.

Menstruasi atau haid adalah peristiwa alamiah yang dialami setiap perempuan. Seorang perempuan yang pertama kali mendapat haid adalah pertanda bahwa ia siap bereproduksi atau menghasilkan keturunan (Golub, 2017). Umumnya datangnya haid pertama kali sekitar umur 10-12 tahun. Haid ini kemudian akan berhenti sama sekali, biasanya sekitar umur 40-50 tahun atau yang disebut menopause. Pada saat seorang bayi perempuan dilahirkan ovariumnya mengandung ratusan ribu sel telur tetapi belum berfungsi. Ketika seorang perempuan memasuki usia pubertas baru ovariumnya mulai berfungsi dan terjadi proses yang disebut dengan siklus menstruasi (Joffres et al., 2013).

Penyuluhan kesehatan adalah kegiatan pendidikan yang dilakukan dengan caramenyebarkan pesan, menanamkan keyakinan, sehingga masyarakat tidak saja sadar, tahu dan mengerti, tetapi juga mau dan bisa melakukan suatu anjuran yang ada hubungannya dengan kesehatan.Dengan cara ini kontak antara klien dengan petugas lebih intensif. Setiap masalah yang dihadapi oleh klien dapat diteliti dan dibantu penyelesaianya. Akhirnya klien tersebut dengan sukarela, berdasarkan kesadaran, dan penuh pengertian akan menerima perilaku tersebut (mengubah perilaku) (Notoatmodjo, 2015)

Oleh karena itu peneliti tertarik untuk melakukan penelitian tentang "Perbedaan Pengetahuan Remaja Putri Kelas X Sebelum dan Sesudh Diberi Penyuluhn Mengenai Menarche dan Menstruasi di SMk Bhakti Mulia Tahun 2020“.

\section{METODE PENELITIAN}

Metode yang digunakan dalam penelitian adalah rancangan eksperimen dengan quasi eksperimen, dengan menggunakan one group pre post test. Rancangan penelitian menggunakan survey cross sectional (Murti, 2013). Variable dalam penelitian dibagi menjadi dua, yaitu variable bebas (penyuluhan) dan variable terikat (pengetahuan remaja putri tentang menarche dan menstruasi ). Populasi penelitian adalah 149 remaja putri kelas X SMK Bhakti Mulia Kediri. Sampel penelitian diperoleh menggunakan rumus metode Slovin yaitu berjumlah 60 remaja putri. Teknik pengambilan sampling menggunakan purposive sampling. Waktu penelitian pada bulan Januari 2020 dan tempat penelitian di SMK Bhakti Mulia Kediri. Instrument yang digunakan adalah kuesioner untuk mengukur pengetahuan remaja putri. Uji analisis yang digunakan adalah $t$-test paired dengan menggunakan software SPSS 23. 


\section{HASIL DAN PEMBAHASAN}

\section{HASIL}

Berdasarkan hasil analisis data penelitian dapat dijabarkan distribusi frekuensi dari masing-masing variable serta tabulasi silang antar variable.

Gambar 1 Pengetahuan Remaja Putri Sebelum Diberikan

Penyuluhan Mengenai Menarch dan Menstruasi

Berdasarkan gambar diatas menunjukan bahwa sebagaian besar remaja putri pengetaahuan terhadap menarche dan menstruasi adalah berpengetahuan baik yaitu 35 remaja putri atau 58,33\%, pengetahuan cukup baik 21 remaja putri atau 35\%, sedangkan yang berpengetahuan kuranag baik 4 remaja putri atau 6,66\%.

Gambar 2 Pengetahuan Remaja Putri Sesudah Diberikan

Penyuluhan Mengenai Menarch dan Menstruasi

Berdasarkan diagram diatas menunjukan bahwa sebagaian besar remaja putri berpengetahuan baik setelah diberi penyuluhan mengenai menarche dan menstruasi yaitu sebanyak 52 remaja putri atau $86,66 \%$, pengetahuan cukup sebanyak 8 remaja putri atau $13,33 \%$, sedangkan yang berpengetahuan kurang tidak ada. 
Tabel 1. Distribusi Frekuensi Pengetahuan Remaja Putri Mengenai Menarch dan Menstruasi di SMK Bhakti Mulia Tahun 2020

\begin{tabular}{cccccccc}
\hline Pengetahuan Remaja & \multicolumn{4}{c}{ Penyuluhan } & \multicolumn{2}{c}{ Peningkatan } \\
\cline { 2 - 5 } Putri Kelas X & \multicolumn{2}{c}{ Sebelum } & \multicolumn{2}{c}{ Sesudah } & & \\
\cline { 2 - 5 } & Frek & $\%$ & Frek & $\%$ & Frek & $\%$ \\
\hline Pengetahuan Baik & 35 & 58.34 & 52 & 86.66 & & 17 & 28.33 \\
Pengetahuan Cukup & 21 & 35.00 & 8 & 13.34 & 14 & 21.67 \\
Pengetahuan Kurang & 4 & 6.66 & 0 & 0 & 4 & 6.66 \\
Jumlah & 60 & 100 & 60 & 100 & 35 & 56.66 \\
\hline
\end{tabular}

Tabel 1 menunjukkan ada peningkatan pengetahuan remaja putri sesudah diberi penyuluhan mengenai menarche dan menstruasi dengan peningkatan sebanyak $28,33 \%$ berpengetahuan baik, 21,67\% berpengetahuan cukup, dan 6,66\% untuk peningkatan pengetahuan kurang.

Tabel 2. Distribusi Frekuensi Perbedaan Pengetahuan Remaja Putri Mengenai Menarch dan Menstruasi di SMK Bhakti Mulia Tahun 2020

\begin{tabular}{ccccc}
\hline Mean & Lower & Upper & $\mathrm{T}$ & $\mathrm{p}$ \\
\hline-7.133 & -9.871 & -4.395 & -5.214 & .000 \\
\hline
\end{tabular}

Tabel 2 menunjukkan Hasil uji statistik dengan menggunakan uji t-tes paired didapatkan nilai $=0,000$ dengan demikian pada tingkat kepercayaan $95 \%$, $=5 \%$ maka nilai $\mathrm{p}$ value $(0,000)<(0,05)$ sehingga Ho ditolak sehingga dapat disimpulkan bahwa ada perbedaan pengetahuan remaja putri sebelum dan sesudah diberi penyuluhan mengenai menarche dan menstruasi di SMK Bhakti Mulia.

\section{PEMBAHASAN}

Hasil penelitian menunjukkan analisa bivariat menggunakan uji t-tes paired menghasilkan rata- rata perbedaan nilai pengetahuan tentang menarche dan menstruasi sebelum dan sesudah diberi penyuluhan -7.13333 dan nilai 0,000 dengan demikian pada tingkat kepercayaan $95 \%,=5 \%$ maka nilai p value $(0,000)<(0,05)$ sehingga Ho ditolak. Sehingga dapat disimpulkan ada perbedaan pengetahuan remaja putri sebelum dan sesudah diberi penyuluhan, sehingga Ho ditolak dan Ha diterima.

Usaha yang dapat dilakukan untuk meningkatkan pengetahuan remaja putri kelas X di SMK Bhakti Mulia adalah dengan cara memberikan penyuluhan dan informasi mengenai pendidikan kesehatan terutama menarche dan menstruasi kepada remaja putri awal sehingga mereka dapat mengetahui dan siap secara mental bila mengalami menstruasi.

Adanya perbedaan pengetahuan remaja putri kelas $X$ sebelum dan sesudah diberi penyuluhan mengenai menarche dan menstruasi di SMK Bhakti Mulia Tahun 2020, sependapat dengan penelitian Hardiningsih yang menyatakan ada pengaruh positif adanya penyuluhan tentang menstruasi terhadap tingkat kecemasan menghadapi menarche pada remaja putri di SDN Mangkubumen Lor No. 15 Surakarta. Dengan uji statistik $\mathrm{t}$ Test Independen menunjukkan $\mathrm{t}$ hitung 5,033 dengan $\mathrm{df}=60, \mathrm{t}$ tabel $=2,000$ dan nilai $\mathrm{p}=0,000$, dimana nilai $\mathrm{p}<0,05(0,000<$ 
$0,05)$ atau $t$ hitung $>t$ tabel $(5,033>2,000)$ artinya ada perbedaan yang bermakna antara tingkat kecemasan kelompok perlakuan dengan kelompok kontrol.

Peningkatan pengetahuan akan tergantung pada sejauh mana pesan yang terkandung dalam pendidikan kesehatan dan penyuluhan, diperhatikan, dipahami dan diterima. Salah satu cara agar remaja putri bisa menerima pesan adalah dengan memberikan pengertian dan penjelasan sejelas mungkin mengenai menarche dan menstruasi dengan diberikan lembar bacaan atau leafleat, lembar balik atau flipcard, mungkin dengan alat peraga yang menarik dan memiliki nilai serta mudah dipahami oleh remaja putri (Srinivas, 2016). Penyuluhan kesehatan dalam promosi kesehatan sebagai upaya meningkatkan pengetahuan dan kesadaran, di samping pengetahuan sikap dan perbuatan. Oleh karena itu, tentu diperlukan upaya penyediaan dan penyampaian informasi, yang merupakan bidang garapan penyuluhan kesehatan. Makna asli penyuluhan adalah pemberian penerangan dan informasi (Chandra-Mouli \& Patel, 2017).

Hal ini didukung oleh teori (Notoatmodjo, 2015)bahwa factor yang mempengaruhi tingkat pengetahuan yaitu pendidikan yang merupakan upaya untuk memberi pengetahuan, sehingga terjadi perubahan perilaku positif yang meningkat. Seseorang memiliki sumber informasi yang lebih banyak maka akan mempunyai pengetahuan yang luas. Informasi juga mempengaruhi tingkat pengetahuan seseorang, informasi dapat diperoleh dari beberapa sumber antara lain TV, radio, Koran, kader, bidan, puskesmas, dan majalah. Menurut teori bahwa akan memiliki pengetahuan baik apabila seseorang mendapatkan informasi yang banyak baik secara lisan maupun tulisan dan pengalaman juga memiliki peran penting karena mempengaruhi pengetahuan seseorang, pengetahauan juga diperoleh dari fakta dengan melihat dan mendengar $\mathrm{TV}$, radio, dan sebagainya (Sarika Manhas et al., 2017)(Lestari, Armini, Mariyanti, \& Yunitasari, 2020).

\section{KESIMPULAN}

Data menunjukkan pengetahuan remaja putri kelas VII sebelum dilakukan penyuluhan remaja putri yang berpengetahuan baik yaitu 35 remaja putri atau $58,33 \%$, dengan nilai rata-rata 73.0667. pengetahuan ramaja putri sesudah diberi penyuluahn didapatkan yang berpengetahuan baik sebanyak 52 remaja putri atau $85,66 \%$, dengan nilai rata-rata 80.2000 . Ada perbedaan pengetahuan remaja putri kelas VII sebelum dan sesudah diberi penyuluhan mengenai menarche dan menstruasi 7.13333 dan nilai 0,000,dengan nilai kenaikan sebanyak $28,33 \%$.

\section{SARAN}

Studi lebih lanjut disarankan untuk menganalisis berbagai faktor yang berhubungan dengan tingkat pengetahuan remaja. Seperti misalnya penambahan faktor lingkungan di sekitar remaja yang beragam dan dikondisikan dengan kesehatan masyarakat di sekitar tempat tinggal remaja tersebut. 


\section{DAFTAR PUSTAKA}

Ameade, E. P. K., \& Garti, H. A. (2016). Relationship between Female University Students' Knowledge on Menstruation and Their Menstrual Hygiene Practices: A Study in Tamale, Ghana. Advances in Preventive Medicine, 2016, 1-10. https://doi.org/10.1155/2016/1056235

Chandra-Mouli, V., \& Patel, S. V. (2017). Mapping the knowledge and understanding of menarche, menstrual hygiene and menstrual health among adolescent girls in lowand middle-income countries. Reproductive Health, Vol. 14. https://doi.org/10.1186/s12978-017-0293-6

Diaris, N. M., \& Pramita, I. (2019). STUDI KUALITATIF PENGALAMAN, PERSEPSI, DAN KESIAPAN ANAK DALAM MENGHADAPI MENARCHE DINI. Jurnal Kesehatan Terpadu, 3(1). https://doi.org/10.36002/jkt.v3i1.712

Erbil, N., Felek, N., \& Karakaşlı, E. (2015). The relationship between attitudes towards menarche and current attitudes towards menstruation of women: A comparative study. International Journal of Human Sciences, 12(2), 1120. https://doi.org/10.14687/ijhs.v12i2.3239

Golub, S. (2017). Menarche: The beginning of menstrual life. In Lifting the Curse of Menstruation: A Feminist Appraisal of the Influence of Menstruation on Women's Lives (pp. 17-36). https:/ / doi.org/10.4324/9781315866116

Joffres, M., Falaschetti, E., Gillespie, C., Robitaille, C., Loustalot, F., Poulter, N., ... Campbell, N. (2013). Hypertension prevalence, awareness, treatment and control in national surveys from England, the USA and Canada, and correlation with stroke and ischaemic heart disease mortality: A cross-sectional study. BMJ Open, 3(8), 1-10. https://doi.org/10.1136/bmjopen-2013-003423

Khan, S., Jha, D., \& Ansari, N. (2020). Menstrual Hygiene Knowledge, Practices and Acne Problems Among Adolescent and Young Adult Females: A Cross Sectional Study. International Journal of Emerging Technologies and Innovative Research, 7(6), 221-228. Retrieved from http://www.jetir.org/papers/JETIR2006036.pdf

Kobayashi, M., Koyama, T., Yasutomi, Y., \& Sankai, T. (2018). Relationship between menarche and fertility in long-tailed macaques (Macaca fascicularis). Journal of Reproduction and Development, 64(4), 337-342. https:// doi.org/10.1262/jrd.2017-164

Lestari, D. P., Armini, N. K. A., Mariyanti, H., \& Yunitasari, E. (2020). The correlation between knowledge and menstrual hygiene practices in children with early menarche. International Journal of Psychosocial Rehabilitation, 24(2), 4172-4180. https://doi.org/10.37200/IJPR/V24I2/PR200739

Murti, B. (2013). Prinsip dan Metode Riset Epidemiologi. Yogyakarta: Gadjah Mada University.

Nehulkar, P., Holambe, V., \& Thakur, N. (2016). Knowledge, attitude and practices of adolescent girls regarding menstruation: A community based cross sectional study. Imternational Journal of Recent Trends in Science and Technology, 17(3), 266-269.

Notoatmodjo, P. (2015). Konsep Perilaku dan Perilaku Kesehatan. Biomass Chem Eng, $49(23-6), 4-28$.

Riskesdas. (2018). Hasil Utama Laporan Riskesdas 2018 [Main Report of Indonesia Basic Health Research 2018]. National Institute of Health Reseach and Development Jakarta. https:/ / doi.org/1 Desember 2013

Sarika Manhas et al., S. M. et al. . (2017). Knowledge about Menarche and Menstruation among Tribal Females of Kargil. International Journal of Agricultural Science and Research, 7(5), 605-612. https://doi.org/10.24247/ijasroct201771

Srinivas, P. (2016). Perception, Knowledge and Practices Regarding Menstruation among School Going Girls in Karaikal. IOSR Journal of Dental and Medical Sciences (IOSR- 
JDMS), 15(1), 27-34. https:// doi.org/10.9790/0853-15192734

V., S., E., G., \& A, O. (2010). Attitude, behaviour and knowledge regarding menarche and menstruation in adolescent schoolgirls in Kayseri. Turkiye Klinikleri Jinekoloji Obstetrik, 20(2), 77-83. Retrieved

from http://jinekoloji.turkiyeklinikleri.com/download_pdf.php?id=57508\%0Ahttp:/ / ovi dsp.ovid.com/ovidweb.cgi?T=JS\&PAGE=reference\&D=emed12\&NEWS=N\&AN=35 8635121 